\title{
EFICIÊNCIA DE DOIS TIPOS DE ISCA PARA CAPTURA DO CAMARÃO DE ÁGUA DOCE MACROBRACHIUM JELSKII (MIERS, 1877) (CRUSTACEA, DECAPODA, PALAEMONIDAE): UM ESTUDO EXPERIMENTAL EM UMA LAGOA URBANA
}

\author{
Damasceno, V.E.S. ${ }^{1,}$; Pinheiro, J.S. ${ }^{1}$ \& Pralon, B.G.N. ${ }^{1}$ \\ ${ }^{1}$ Universidade Federal do Piauí (UFPI), Campus Ministro Petrônio Portella, Laboratório Zoologia, \\ uso e conservação da fauna ecotonal da América do Sul (ZUCON). \\ *Autor correspondente: victor.nzo@outlook.com
}

\begin{abstract}
Macrobrachium jelskii (Miers, 1877), com ciclo de vida completamente dulcícola, é uma das espécies de camarão mais comuns e amplamente distribuída na América do Sul dentre o gênero Macrobrachium (Bates, 1868). Apesar de existirem alguns estudos sobre a biologia e ecologia desta espécie, pouco se sabe sobre seus hábitos alimentares e preferência trófica. O objetivo do presente trabalho foi verificar preferência entre dois tipos de oferta alimentar por parte de M. jelskii de acordo com o sexo, tamanho e peso. As coletas foram realizadas uma vez por mês, entre setembro e novembro de 2017 no Parque Lagoas do Norte, Teresina, Estado do Piauí. Em uma das lagoas, escolhemos três pontos amostrais com espaço entre eles de 50m, onde em cada um colocamos duas armadilhas, uma com isca de peixe e outra com "ralão" (ou farelo) de coco Babaçu (Attalea speciosa), totalizando seis armadilhas. As armadilhas eram deixadas no crepúsculo e retiradas da água ao amanhecer. Em laboratório os indivíduos foram identificados, pesados, sexados e mensurados quanto ao comprimento do cefalotórax (CC, em mm). Do total de 963 indivíduos coletados, 436 foram obtidos com isca de peixe e 527 com isca de Babaçu. Quanto à abundância total de indivíduos capturados não houve preferência por tipo de isca ( $p>0,05)$. Com relação ao CC e peso do total dos indivíduos capturados, percebemos preferência dos indivíduos maiores e mais pesados pela isca de Babaçu $(p<0,01)$. Mesmo com a proporção dos indivíduos que entraram nas armadilhas para ambos os tipos de iscas não tendo diferenças estatísticas significativas, as armadilhas com isca de Babaçu atraíram indivíduos maiores e mais pesados, consequentemente adultos em estágio avançado da ontogenia. Isto indica que possivelmente ocorre nesta população uma mudança de hábito alimentar de acordo com o aumento de tamanho e peso dos indivíduos de M. jelskii.
\end{abstract}

Palavras-chave: Babaçu, hábito alimentar, Lagoas do Norte. 